\title{
Competência Central e Lógica Dominante: contribuições à análise de processos de fusão e aquisição
}

\author{
Marcelo Pereira Binder ${ }^{1}$ \\ Emerson Antonio Maccari ${ }^{2}$ \\ Luiz Felipe Nasser-Carvalho ${ }^{3}$
}

\section{Resumo}

Fusões e aquisições figuram entre as decisões estratégicas mais importantes que uma empresa pode tomar. Nas décadas de 1980 e 1990, os processos de fusão e aquisição ocorreram em grande número e diversas teorias foram desenvolvidas para explicar o fenômeno. Contudo, essas teorias, em sua maioria, estão relacionadas à área financeira, sendo que os aspectos não quantificáveis, como as competências centrais e a lógica dominante, têm sido relegados a segundo plano. Identificada essa lacuna, este trabalho propõe a inserção do conceito da competência central e lógica dominante como elementos de análise para avaliar um processo de fusão. Para isso, o presente artigo resgatou a discussão desses conceitos no campo da estratégia empresarial e analisou, sob esta ótica, um caso que não alcançou os objetivos propostos com a fusão. O estudo encontrou elementos que permitiram concluir que a adoção dos conceitos de competência central e de lógica dominante ajuda a explicar com uma nova luz o processo de fusão.

Palavras-chave: Estratégia. Fusões e Aquisições. Competência Central. Lógica Dominante.

\footnotetext{
${ }^{1}$ Doutor pela EAESP/FGV e Professor do Programa de Mestrado e Doutorado em Administração da Universidade Nove de Julho - UNINOVE. Endereço: Av. Francisco Matarazzo 612 -Água Branca - São Paulo - SP - Brasil. CEP: 05001-100. E-mail: binder@uol.com.br.

${ }^{2}$ Doutor pela Universidade de São Paulo - USP e Professor do Programa de Mestrado e Doutorado em Administração da Universidade Nove de Julho - UNINOVE. Endereço: Av. Francisco Matarazzo 612 - Água Branca - São Paulo - SP - Brasil. CEP: 05001-100. E-mail: emersonmaccari@gmail.com.

${ }^{3}$ Doutorando pela University of Warwick. Mestre pela Fundação Getúlio Vargas -EAESP/FGV. The University of Warwick. CV47AL-CoventryGrã-Bretanha.E-mail: luiznasser@gmail.com.

Artigo recebido em: 21/07/2010. Aceito em: 21/09/2010. Membro do Corpo Editorial Científico responsável pelo processo editorial: Rolando Juan Soliz Estrada.
} 


\section{Introdução}

Neste artigo, pretende-se contribuir com uma nova visão às pesquisas em fusões e aquisições agregando a perspectiva da lógica dominante (PRAHALAD; BETTIS, 1985) e da competência central (PRAHALAD; HAMEL, 1990).

Diversos pesquisadores procuram identificar por que e como as fusões acontecem, quais são os fatores que impulsionam os processos de fusão, quais são os pontos de atrito no processo de integração, $e$ também por que alguns processos de fusão falham. No entanto, como veremos em nossa revisão de literatura, nos estudos empíricos de diversas perspectivas teóricas sobre fusões e aquisições, os aspectos organizacionais não mensuráveis são deixadas de lado. Devido a esses estudos, há algumas evidencias de que olhar somente para os fatores objetivos dentro de um processo de fusão (business case financeiro, fusão de processos, sistemas e políticas, reavaliação do portfólio de produtos e serviços, etc.) pode não ser suficiente para prever e explicar o fracasso ou o sucesso. A análise da lógica dominante (PRAHALAD; BETTIS, 1985) e da competência central (PRAHALAD; HAMEL, 1990) das empresas envolvidas nesses processos surge, então, como um elemento, fértil para a compreensão dos aspectos mais subjetivos dos fatores de sucesso $e$ fracasso de uma fusão ou aquisição.

O artigo está estruturado da seguinte forma: inicialmente, foi realizada uma revisão da literatura. Em seguida, descreve-se a metodologia e o processo de fusão das áreas de consultoria da Coopers\&Lybrand Brasil e da Arthur Andersen Brasil. Então, verifica-se como a lógica dominante (PRAHALAD; BETTIS, 1985) e a competência central (PRAHALAD; HAMEL, 1990) de cada uma dessas firmas se comportam no caso de fusão analisada. A partir disso, são apresentadas a análise e a discussão. Finalmente, há as conclusões que apontam para a necessidade do entendimento lógico dominante e da competência central dentro da dinâmica do processo de fusão com base nos problemas organizacionais decorrentes da análise do processo como um todo.

\section{Revisão da Literatura}

As fusões e as aquisições figuram entre as mais importantes decisões estratégicas que uma empresa pode tomar, e isso gerou uma série de pesqui- 
sas a respeito do assunto. Na perspectiva teórica de Financial Economics, pesquisas empíricas têm demonstrado resultados desapontadores dos processos de fusão sob as perspectivas econômica e financeira (FOWLER; SMITH, 1988). No mesmo sentido, levantamentos como os da revista americana Business Week (1999) mostram que mais de 50\% das empresas que passaram por processos de fusão reduziram seu valor no mercado acionário. Outro estudo da empresa de consultoria McKinsey (1994) mostrou que 61\% das empresas que passaram por processo de fusão obtiveram retornos inferiores ao custo de capital.

Com relação aos resultados das fusões, alguns autores argumentam que se a fusão ocorre entre empresas com atividades de negócios relacionadas, haverá maior chance do processo alcançar resultados positivos (DATTA, 1991). Outros autores não encontraram nenhum tipo de relação consistente entre essas variáveis (FOWLER; SMITH, 1988; HUNT, 1990; LUBATKIN, 1987; MONTGOMERY; WILSON, 1986).

Em um processo de fusão e aquisição, a organização deve considerar os limites da racionalidade e a maneira como o processo pode ser afetado por esses limites (MARCH; SIMON, 1958). Tais limites de racionalidade podem inibir a consideração de alternativas de ação, que, de outro modo, seriam relevantes. As organizações podem melhorar seu desempenho em processo de fusão e aquisição, na medida em que se tornam mais conscientes dos limites da racionalidade, possibilitando com isso uma redução no tempo de integração entre empresas. Ainda que definido na década de 1950, a noção de racionalidade limitada se tornou um modelo muito influente na teoria, gerando diversas aplicações, entre as quais encontram-se mais recentemente as noções de Lógica Dominante (PRAHALAD; BETTIS, 1986; BETTIS; PRAHALAD 1995) que por sua vez influencia a definição de Competência Central (HAMEL; PRAHALAD, 1990). Essas noções baseiam-se na ideia de que por não ser apto a lidar com toda a complexidade do ambiente extra e intraorganizacional, administradores, individual e coletivamente, desenvolvem visões especificas da realidade. Essas visões que podem ser do ambiente, da organização e das relações entre ambos passam a balizar o entendimento do passado, as ações presentes e as perspectivas futuras.

Dentro dessa perspectiva, em um processo de fusão haverá diferentes percepções das ameaças e oportunidades no ambiente externo e da forma de responder a elas. Portanto, ignorar tais variáveis (per se mais subjetivas) é ignorar um elemento crucial do processo decisório e da ação gerencial. 
Prahalad (1976) em Strategic choices in diversified MNCs, publicado na HBR, aponta o papel do gerenciamento de uma empresa multinacional que deve basear-se no gerenciamento do poder relativo gerado da disputa de uma parte em relação à outra, dentro da matriz global.

Cabe à alta gerência deslocar "poder relativo" ao "lócus" que se julgue mais apropriado para a estratégia global da empresa. Para fazer isso eficientemente, é necessário entender os conflitos de necessidades e interesses dentro da matriz global de organização da empresa, grande parte da discussão gira em torno de conflitos sobre orientações globais e regionais, linhas de produtos e subordinações, graus de liberdade e controle levando à inter-relação entre diversidade e interdependência (PRAHALAD, 1976, p. 78).

O autor analisa uma empresa global que denomina-se Beta, interpretando modelos de escolha estratégica em seis diferentes áreas: investimento, sistemas de controle, joint-venture, mobilidade e desenvolvimento gerencial, fusões e aquisições e finanças. No desenvolvimento gerencial, pode-se encontrar os primeiros traços do que mais tarde virá a ser Lógica Dominante e depois se desenvolve gerando o conceito de competência central

[...] os executivos mais e mais compartilham uma identidade comum, experiências comuns e conhecimento baseado em uma contínua interação uns com os outros (PRAHALAD, 1976, p. 73).

Doz e Prahalad (1981) procuram desenvolver um framework mostrando como a matriz de uma MNCs pode ganhar controle sobre suas subsidiárias por meio do uso de uma série de mecanismos administrativos. Os três conjuntos de mecanismos administrativos são: (1) gerenciamento de dados; (2) gerenciamento dos gerentes e; (3) resoluções de conflito. Esses mecanismos devem ser usados para mudar a orientação cognitiva e a estratégica dos gerentes das subsidiárias, para os autores essa mudança na orientação "cognitiva" e estratégica é a chave para se ter controle sobre as unidades. Interpreta-se isso como o desenvolvimento inicial da ideia de competência central em uma organização. Os autores terminam concluindo que é insuficiente dividir a estratégia entre formulação e implementação, mas sim desen- 
volver mecanismos gerenciais que mudem os relacionamentos de poder dentro da companhia. A metodologia que os autores empregaram foi o estudo de caso que durante seis anos foi realizado por eles e com alguns alunos de doutorado nas seguintes empresas: Ericsson, Brown Boveri, GTE, GM, Ford, Corning Glass Works, Iveco e Alcan.

Prahalad e Bettis (1986) constroem o conceito da lógica dominante a partir da problemática do gerenciamento de unidades de negócio diversificadas, agregando aspectos da psicologia cognitiva e utilizando as noções de "esquemas" mentais. Ou seja, a unidade central ou corporativa por meio de seus sistemas de conhecimentos e crenças individuais toma decisões na alocação de recursos nas unidades de negócios. Nesse sentido, os autores definem a lógica dominante como:

A dominant general logic is the way which managers conceptualize the business and made critical resource allocation decisions, be it in technologies, product development, distribution, advertising, or in human resource management. (PRAHALAD; BETTIS, 1986, p. 490).

A questão central colocada pelos autores é a de que algumas empresas conseguem boa performance em suas unidades de negócio diversificadas e outras não. A resposta sugerida é a de que a performance pode ser explicada pela forma que os gestores do negócio central definem como os recursos devem ser alocados. Segundo essa argumentação, o gestor de uma organização possui uma forma de ver o funcionamento (esquemas mentais) do mundo e propor ações apropriadas para as demandas que ele encontra $e$ interpreta. Esses esquemas mentais não são expressos de forma consciente, pois são desenvolvidos de acordo com a experiência do indivíduo, ou seja, a forma com que ele aprende a lidar com as situações às quais é exposto. $\mathrm{O}$ esquema mental compartilhado pela organização é a base da lógica dominante. Prahalad e Bettis (1986) argumentam que a lógica dominante aprendida no negócio central pode ser muito apropriada a esse negócio, mas, quando a organização diversifica seus negócios, essa lógica pode não ser a mais adequada para a nova unidade de negócio, e o time gerencial da unidade central deverá modificar a antiga lógica dominante ou aprender uma nova lógica para que a unidade de negócios obtenha boa performance. Essa 
performance tem relação com a capacidade do time gerencial adquirir as competências requeridas pelas novas unidades de negócio.

Para os autores, o que determina o desempenho das firmas não é o tipo de diversificação (correlata ou não correlata), mas, como o "top management" determina a alocação dos recursos nas unidades de negócio diversificadas. Se essa alocação de recursos é adequada ao novo negócio e não ao negócio central em que a lógica foi desenvolvida, provavelmente a organização será bem-sucedida.

Dez anos depois, Bettis e Prahalad (1995), após o primeiro artigo receber o prêmio de melhor do Strategic Managment Journal, em 1986, retomam o tema da lógica dominante em 1995, passando o ponto de discussão da problemática do gerenciamento das unidades de negócios diversificadas para a mudança no ambiente organizacional. Os autores questionam por que algumas empresas não são capazes de enxergar as mudanças no ambiente, $e$, quando enxergam, por que não conseguem se adaptar a ela.

Bettis e Prahalad (1995) argumentam que mesmo com o grande incremento na tecnologia da informação, que possibilita aos gerentes uma maior quantidade de informação, o processo de tomada de decisão nas organizações não melhorou. Segundo os autores, isso ocorre devido à lógica dominante da organização (os esquemas mentais compartilhados pela equipe dirigente) funcionar como um filtro, um funil, que seleciona e modifica informações que são captadas no ambiente em que a própria demanda por informação passa a ser definida previamente.

Prahalad e Hamel (1990) desenvolvem o conceito da competência central da corporação (Core Competence), eles definem competência central como um aprendizado coletivo da organização, especialmente como coordenar diversas habilidades de produção e integrar múltiplas correntes de tecnologia.

Segundo os autores, para serem essenciais, as competências devem responder a três critérios: (a) uma competência central deve ser versátil e proporcionar acesso a uma ampla variedade de mercados; (b) oferecer reais benefícios aos consumidores; e (c) ser difícil de imitar e prover acesso a diferentes mercados. Uma competência central não é constituída por uma habilidade ou tecnologia isolada, mas sim por uma complexa harmonização de múltiplas habilidades e tecnologias (PRAHALAD; HAMEL, 1990).

O domínio de um determinado conjunto de competências centrais irá definir em quais produtos a empresa pode buscar participação no mercado 
com possibilidade de sucesso. Desse modo, a compreensão das competências centrais de um setor ou empresa atua não apenas restringindo, mas também focalizando o horizonte de atuação competitiva deste setor ou empresa, adicionando à questão das decisões estratégicas uma nova dimensão de análise.

Os autores usam a metáfora de uma grande árvore para descrever a organização diversificada, em que o tronco e os galhos principais são os produtos essenciais da organização, os galhos menores são as unidades de negócio e as folhas, flores e frutos são os produtos finais, e, ainda, a competência central é a raiz que alimenta a árvore.

Prahalad e Hamel (1990) acreditam que as unidades de negócio devem mudar a forma pela qual são gerenciadas e expandir sua forma de administrar para além da unidade de negócios, pois as corporações deveriam, assim como têm uma carteira de produtos e negócios, ter uma carteira de competências. E a administração focada na unidade de negócios atrapalha o desenvolvimento de competências essenciais para a corporação. Isso ocorre porque elas procuram somente a maximização do lucro interno da unidade e buscam inovações que estiverem à mão como a simples melhoria de produtos, ou então, procuram fazer pequenas expansões geográficas de seus mercados. Nesse sentido, a corporação deve desenvolver uma arquitetura estratégica baseada na competência central que dê a lógica para a diversificação do produto e do mercado, revelando uma direção ampla, mas sem expor cada passo.

A seguir será analisado o caso brasileiro de fusão entre duas empresas prestadoras de serviços profissionais. A intenção é realizar uma observação empírica dos conceitos discutidos até o momento.

\section{Metodologia e Cenário da Pesquisa}

A metodologia desta pesquisa foi o estudo de caso, realizado por meio de investigação empírica sobre um fenômeno contemporâneo dentro de seu contexto da vida real e das condições contextuais. O estudo se baseia em um caso único por meio de várias fontes de evidências e beneficia-se do desenvolvimento prévio de proposições teóricas para conduzir a coleta e análise dos dados (YIN, 2001). A estratégia de pesquisa buscou o entendimento de um presente dinâmico com um conjunto de singularidades (EISENHARDT, 1989). 
Seguindo procedimentos propostos por Yin (2001) para a coleta de dados, foram utilizadas duas fontes, a saber, documentação e entrevistas em profundidade. Em relação à documentação, foram identificados artigos em jornais e revistas de negócio no período relativo à fusão e documentos internos das duas empresas envolvidas. A fonte de informações mais rica $e$ importante, no entanto, foram as entrevistas em profundidade.

Nessa direção, entrevistou-se os executivos de diversos níveis e com origens distintas em relação à empresa, e que faziam parte dessa empresa antes da fusão ocorrer. Realizou-se a triangulação dos dados buscando a convergência de informações, a fim de verificar a validade do construto (YIN, 2001; EISENHARDT, 1989).

As duas empresas, Coopers\&Lybrand e Arthur Andersen, objetos deste estudo, possuíam cerca de mil funcionários cada, ambas tinham seu escritório central localizado na cidade de São Paulo e escritórios regionais nas principais cidades brasileiras, especialmente escritórios de serviços de auditoria. As duas eram empresas transnacionais com sócios locais responsáveis por seu gerenciamento. $\mathrm{O}$ foco de análise recaiu não sobre a empresa como um todo (suas diversas práticas), mas suas divisões de consultoria empresarial. A opção por analisar essa área específica se deve ao fato do serviço de consultoria das duas empresas possuírem maiores particularidades e complexidade do que os demais de serviços prestados. Em geral, os serviços de auditoria seguem a legislação e são similares em todas as empresas.

O anúncio do processo de integração ocorreu em setembro de 1998. Nesse mesmo ano as duas empresas passaram a integrar as rotinas administravas e estruturas de carreiras. Em fevereiro de 1999, as empresas passaram a dividir o mesmo espaço físico. A empresa resultante do processo de fusão foi denominada Arthur Andersen Business Consulting que operou até 2002 quando foi liquidada devido aos desmembrados do caso de fraude contábil da Enron. 


\section{Estudo de Caso - Fusão Coopers\&Lybrand e Arthur Andersen Brasil}

\subsection{Coopers\&Lybrand Brasil}

A Coopers\&Lybrand passava, na época, por um processo de fusão mundial com uma outra grande empresa do setor, a Price Waterhouse (que viria a se tornar mais tarde a PriceWaterhouseCoopers - PwC). Entretanto, no Brasil, a realidade local mostrou dificuldades ao processo de fusão devido à sobreposição dos escritórios regionais de auditoria e de outras linhas de serviços similares. Também, o escritório brasileiro da Price Waterhouse era o maior do país no setor e a diferença de porte dificultava a chamada "fusão entre iguais".

Os sócios da Coopers\&Lybrand no Brasil, que possuíam autonomia devido ao fato da empresa atuar como uma rede, depois de analisarem o processo de fusão local, decidiram por não acompanhar a fusão mundial. Com essa decisão surgiu um novo problema: a Coopers\&Lybrand Brasil iria perder sua bandeira mundial (nome Coopers\&Lybrand), e isso para uma empresa desse ramo, com uma boa estrutura organizacional, é fundamental. Passou-se então a procurar associação a um grande nome internacional.

\subsection{Arthur Andersen}

A Arthur Andersen passava por um momento de crescimento aproveitando o bom ciclo econômico brasileiro (1997-1998). Procurava aumentar sua presença no território nacional e desenvolver novas linhas de serviços. O escritório brasileiro era relativamente pequeno, mas fazia parte de uma das maiores e mais antigas empresas de serviços de auditoria do mundo. No mercado brasileiro, a Arthur Andersen procurava aumentar os tipos de serviços prestados, pois na época, estava muito concentrada em auditoria, o que apresentava taxas de serviço com baixa margem de lucro. Nesse sentido, a empresa procurava crescer rapidamente e também expandir sua linha de serviços.

Diferentemente da Coopers\&Lybrand, a Arthur Andersen atuava como uma única empresa no mundo, dentro da organização e em seus folhetos publicitários, o tema central era a inscrição "one firm" (empresa única). Nessa mesma época, a Arthur Andersen passava por um processo de cisão mundial 
com uma de suas linhas de serviços, a área de consultoria se desconectava do restante da empresa, dando vida à Andersen Consulting, atualmente Accenture. Essa cisão estava ocorrendo, em grande medida, por conflitos de natureza política e financeira entre os altos escalões das divisões de consultoria e de auditoria. Os honorários de consultoria eram substancialmente maiores e mais rentáveis do que os de auditoria.

\subsection{O Anúncio da Fusão}

O ambiente de incerteza na Coopers\&Lybrand sobre os rumos que a empresa tomaria no país acarretou na saída de um sócio e de um grupo de consultores que posteriormente foram admitidos por um concorrente, o que aumentou a instabilidade para os funcionários. Com isso, antecipou-se o aviso da fusão, todos os consultores foram reunidos em um auditório em que os sócios da Coopers\&Lybrand e da Arthur Andersen anunciaram conjuntamente que a fusão ocorreria e que a nova empresa precisaria de todos para enfrentar os desafios futuros. Nesse momento, foram apresentados aos funcionários da Coopers\&Lybrand os planos da Arthur Andersen para seu crescimento. Como nas palavras de um executivo da Coopers\&Lybrand: "do dia para a noite, eles nos mostraram novos caminhos e eu fingi que gostei para manter meu emprego, tinha que seguir os caminhos deles."

Nos meses seguintes, as empresas mantiveram-se em escritórios separados com equipes separadas, trabalhando em projetos separados. Aos poucos, alguns projetos foram integrando as equipes das duas empresas, mas isso não ocorreu de uma forma intensiva.

Nesse meio tempo, outros sócios, gerentes e consultores deixaram a Coopers\&Lybrand por iniciativa própria, em geral, alegando (ou demonstrando veladamente) discordância sobre a nova política da empresa para irem para a Arthur Andersen. Na Arthur Andersen, ao contrário da Coopers\&Lybrand, não ocorreu nenhuma movimentação de pessoal nesse período: "as mesmas pessoas continuaram a trabalhar da mesma maneira".

\subsection{Junção do Espaço Físico}

Seis meses após o anúncio da fusão, o escritório onde estava instalada a Coopers\&Lybrand foi desocupado e a equipe da Coopers\&Lybrand foi 
transferida para o escritório da Arthur Andersen. Esse escritório havia sido totalmente remodelado para receber os funcionários da Coopers\&Lybrand. Apesar de estarem ocupando o mesmo ambiente, as equipes de consultores provenientes de cada empresa continuavam a ocupar espaços físicos diferentes no escritório, uma vez que não existiam espaços fixos individuais, as pessoas se agrupavam em torno dos colegas advindos de suas empresas de origem, havendo a demonstração clara da "diferença entre nós e eles" refletida na divisão do espaço físico. Cada grupo afirmou mais intensamente sua identidade perante o outro, sendo os membros dos outros grupos não percebidos como indivíduos, mas por meio de estereótipos. Foram criados fortes estereótipos sobre o outro grupo, bem como de si mesmo. A forma que se ocorreu a ocupação do espaço físico é a comprovação de aglutinação em grupos, devido ao choque e à necessidade de autoidentificação. Logo em seguida, surgiram denominações desqualificadoras para um grupo se referir ao outro, os consultores da Arthur Andersen viraram os "Arturzinhos" e os da Coopers\&Lybrand os "Cabeças". Com a denominação "Arthurzinhos", os exmembros da Coopers\&Lybrand queriam indicar pessoas monótonas, esquemáticas e quadradas. Por outro lado, os membros da Arthur Andersen referiam-se a "Cabeças" querendo passar a mensagem de que os exCoopers\&Lybrand eram pessoas sem postura profissional e despreparadas, sem metodologia e que "não estavam a fim de trabalhar pesado". Essas denominações eram internas a cada grupo e muito veladas: ninguém se referia a um indivíduo do outro grupo nesses termos, mas não eram necessárias palavras: formaram-se dois grupos antagônicos que procuravam reforçar suas características menosprezando e diminuindo as características dos demais membros do outro grupo.

Um ponto importante a se destacar nesse choque de grupos é o de que isso não ocorria em pé de igualdade. A Coopers\&Lybrand "invadia" o território da Arthur Andersen e essa por sua vez, "adquiriu" a Coopers\&Lybrand o que criava um sentimento de superioridade no encontro intercultural. Como colocado por um gerente da Coopers\&Lybrand: "fomos violentados, as regras do jogo eram as deles".

Já para um gerente da Arthur Andersen: "Foram implementadas as práticas organizacionais da Arthur Andersen, porque eram mais modernas e adequadas ao negócio e estavam em linha com a orientação internacional". $\mathrm{Ou}$ "estamos elaborando um catch-up de treinamento para nivelar (destaque nosso para distinguir a noção de superior-inferior) o pessoal". 
Como disse um sócio da Arthur Andersen na época da fusão, o "catchup" (ou corrida atrás da recuperação) era um plano de treinamento nas metodologias Arthur Andersen para consultores advindos da Coopers\&Lybrand; ele era sempre visto como enfadonho e desinteressante pelos consultores da Coopers\&Lybrand. Outro instrumento de "nivelamento" era um curso desenvolvido pela Arthur Andersen chamado "The Way We Consult" para iniciar os adquiridos nas "boas práticas" de consultoria.

Os gerentes que antes ocupavam salas individuais agora dividiam baias de trabalho sendo que em cada baia havia um gerente da Coopers\&Lybrand e outro da Arthur Andersen. Vários trabalhos motivacionais e de comunicação foram realizados para integrar as equipes e evitar pontos de atrito. Porém, foram trabalhos com pouco efeito na organização.

A nova empresa de consultoria estava reunida, dividindo um espaço único por seis sócios, um diretor, 25 gerentes e aproximadamente 110 consultores. Apesar de tudo isso, as equipes continuavam a trabalhar separadamente. Isso advinha do fato dos tipos de projetos realizados por cada grupo de origem serem diferentes. A falta de integração dos projetos é um primeiro sinal de choques entre culturas diferentes.

\subsection{Expertise - Diferenças Conceituais sobre o Negócio: a Lógica Dominante e a Competência Central}

Encontrou-se na expertise um forte diferenciador entre as duas empresas, pois a construção dessa expertise foi realizada por formas de atuação e aprendizado diferentes. Essa disparidade pode ser categorizada como diferença entre lógicas dominantes que constroem uma competência central distinta.

A forma com que as pessoas em cada empresa se relacionavam e interpretavam a realidade era discrepante. A Coopers\&Lybrand possuía um tipo de serviço com visão estrutural, ou seja, uma empresa é uma estrutura complexa de elementos objetivos e subjetivos que se inter-relacionam. Por essa visão da realidade, a empresa realizava projetos focados em reestruturação, recursos humanos, supply-chain management e implantação de sistemas, $e$ fazia uso constante de consultores especialistas com experiência no setor industrial, setor em que seus projetos se desenrolavam. Porém, segundo a visão dos consultores da Arthur Andersen: para os da Coopers\&Lybrand "faltava disciplina e metodologia na condução dos projetos". 
Já a Arthur Andersen possuía uma competência central baseada em uma visão processual, ou seja, uma empresa é um conjunto de processos e atividades técnicas que devem funcionar como uma engrenagem perfeita. A partir dessa visão, os principais serviços prestados eram sistemas de custeio $\mathrm{ABC}$, redesenho de processos e implantação de sistemas de informação. Como colocado por um entrevistado da Coopers\&Lybrand: "Se não for $\mathrm{ABC}$, os caras pipocavam, eles eram bons em $\mathrm{ABC}$, mas só isso".

A diferença de foco é fruto da lógica dominante que advém das experiências passadas e formação dos profissionais. A origem dos membros de cada empresa era diferente e isso fazia com que competências distintas fossem desenvolvidas, baseadas em modelos cognitivos diversos.

Na Coopers\&Lybrand todos os sócios e gerentes eram pessoas "formadas" em serviços de consultoria, ou seja, pessoas que iniciaram sua carreira profissional em consultoria ou em determinada indústria, passando para a consultoria já com alguma experiência.

Por outro lado, todos os sócios e gerentes da Arthur Andersen eram exauditores e todos iniciaram sua carreira na empresa na área de auditoria $e$ foram transferidos para a área de consultoria já com "a marca" do negócio auditoria. Como colocado por um entrevistado: "o cara se destacava em auditoria e era convidado para consultoria, sempre se procurou trazer o melhor da auditoria". No entanto, o processo de consultoria possuía características bem diferentes do processo de auditoria. Um é aconselhamento empresarial baseado em uma multiplicidade de conhecimentos e habilidades pessoais, o outro é a verificação de procedimentos e números a partir de normas contábeis e legislação rigorosa.

Nesse caso, a área de origem influencia de forma significativa em como as pessoas interpretam o mundo, os elementos que julgam serem importantes e as soluções de negócio que procuram encontrar. Em outras palavras, as práticas da Lógica Dominante que são desenvolvidas e compartilhadas entre a gerência das empresas foi estimulada e construída de forma diferente. Os elementos que compunham a racionalidade de cada uma das empresas diferem-se por lidar com realidades distintas.

Pode-se definir simplificadamente a Lógica Dominante da Coopers\&Lybrand como: "se uma empresa tem um problema, nós a ajudamos a resolver esse problema"; já na Arthur Andersen essa Lógica Dominante seria representada pela frase: "nós temos uma solução que pode ajudar na gestão de sua empresa". Nesse sentido, a competência central da 
Coopers\&Lybrand pode ser caracterizada como análise organizacional e a da Arthur Andersen normatização processual. Essas diferenças explicam as discrepância do portfólio de serviços. Por exemplo, devido aos membros da Arthur Andersen terem sido formados em auditoria, eles interpretavam a realidade por meio de controles e normas, por isso o desenvolvimento de trabalhos baseados em formalização de processos e controles financeiros. Essa diferença na forma de conceituar o negócio afeta no modo como a empresa implementa sua estrutura de carreira, valorização de determinados perfis e forma de remuneração.

\subsection{Estrutura de Carreira na Empresa, Experiência Média no Negócio e Remuneração}

A diferença das competências centrais e da lógica dominante faz com que a interpretação da realidade ocorra de forma distinta, que as entradas e as saídas sejam díspares o que influencia diretamente nas estruturas de carreira, experiência média no negócio, perfil das pessoas selecionadas para empresa e nível de remuneração.

Esses atributos servem, em boa medida como meios para reforçar a cultura organizacional existente, formando assim um círculo de autoalimentação que deverá se fortalecer com o sucesso contínuo ou quebrar-se com fracassos. Nesse sentido, fica evidente que a divisão "natural" dentro do mesmo espaço físico por tempo prolongado pode ser explicada pelo fato das pessoas possuírem conceitos diferentes do negócio e do mundo em que estão inseridas e, por isso, tenderem a se agrupar em torno daqueles que compartilham seus valores. Isso é uma prova de como a lógica dominante é capaz de fazer com que empresas, apesar do mesmo setor, selecionem pessoas de perfis distintos. A questão que surge aqui é: como integrar pessoas de perfis diferentes que interpretam o mundo de forma díspar? Nesse sentido, como fazer uma organização com duas culturas organizacionais diferentes ter um significado compartilhado, como proposto por Smircich (1983)?

$\mathrm{Na}$ Coopers\&Lybrand, a idade média dos consultores era maior do que na Arthur Andersen e, sabe-se que a experiência prática neste ramo de negócio é muito valorizada. Como afirmou um entrevistado da Coopers\&Lybrand: "Na Coopers\&Lybrand era um pessoal maduro, consistente, ao contrário da Arthur Andersen onde, tirando os sócios e um ou 
outro gerente, era um bando de moleques que acabaram de sair da escola". Outro ponto é que o índice de turnover era menor, e a remuneração era melhor na Coopers\&Lybrand.

Essas diferenças decorrem da forma diferenciada como as empresas viam os recursos humanos. A Coopers\&Lybrand possuía uma maior estabilidade, maior remuneração devido à perspectiva de uma carreira longa em consultoria. Já na Arthur Andersen, a carreira longa era para poucos e a saída com dois ou três anos de casa era o mais comum. Como colocado por um entrevistado da Arthur Andersen: "A garotada entrava lá como um trampolim para outras empresas, queriam aprender rápido e se mandar".

Porém, cabe notar que nesse setor as pessoas são os principais recursos, dado que ocorre a prestação direta de serviços. A competência central da Coopers\&Lybrand buscava pessoas mais maduras com maior capacidade analítica e maior experiência no negócio de consultoria, já a Arthur Andersen valorizava o formalismo, a hierarquia, o comprimento de normas e a capacidade operacional. Isso mostra que existiam diferenças na percepção de como os recursos deveriam ser alocados.

\subsection{Resultado do Processo de Fusão}

A estrutura administrativa e operacional que prevaleceu foi a da Arthur Andersen, que obedecia às diretrizes mundiais. As diferenças de perfil, idade, tempo no cargo e faixa salarial, geraram uma série de "desencaixes" entre as pessoas da Coopers\&Lybrand e da Arthur Andersen, bem como demissões e desligamentos de pessoas advindas da Coopers\&Lybrand. A empresa resultante ficou sem uma identidade clara no mercado e passou a perder clientes. Internamente, a direção era dividida entre um sócio da exCoopers\&Lybrand e outro da Arthur Andersen, mas, para os funcionários, não havia uma clara definição de papéis.

Logo em seguida, dois dos principais sócios advindos da Coopers\&Lybrand deixaram a Arthur Andersen para ir trabalhar na concorrente, PriceWaterhouse, o que causou um choque interno e foi um claro sinal de que a fusão estava com sérios problemas. Houve em seguida, a saída voluntária de mais consultores e gerentes. A direção interna da empresa foi trocada e outro sócio advindo da Arthur Andersen assumiu essa posição, reforçando cada vez mais a percepção de que, ao invés de uma fusão, o que 
se tinha era uma aquisição com tentativa de dominância de uma cultura sobre a outra.

A nova empresa passou por um ano de maus resultados financeiros, em uma época em que a maioria dos concorrentes estava com dificuldades para suprir a demanda do mercado. Devido aos resultados financeiros estarem abaixo do previsto, houve um processo de demissão envolvendo aproximadamente $25 \%$ da força de trabalho, sendo muitos deles provenientes da Coopers\&Lybrand.

Em meados de 2002, menos de $20 \%$ das pessoas originárias da Coopers\&Lybrand estavam na empresa resultante da fusão. Essa empresa não foi capaz de integrar as pessoas no processo de fusão, pois houve uma tentativa de impor uma das culturas, nesse caso a da Arthur Andersen. Tal fato gerou enfraquecimento da empresa como um todo, perdas financeiras e um sentimento generalizado de fracasso da fusão. Em julho, a Andersen encerrou suas operações após o envolvimento no escândalo Enron. A seguir, apresenta-se um quadro resumido com a interpretação dos pontos identificados nas entrevistas realizadas.

\begin{tabular}{|l|l|l|}
\hline \multicolumn{1}{|c|}{ Coopers\&Lybrand } & \multicolumn{1}{|c|}{ Arthur Andersen } \\
\hline Valores & $\begin{array}{l}\text { Trabalho em equipe } \\
\text { Inovação e criatividade } \\
\text { "Amigo" do cliente } \\
\text { Diversidade }\end{array}$ & $\begin{array}{l}\text { Disciplina } \\
\text { Normatização } \\
\text { Padronização de rotinas, } \\
\text { processos e procedimentos } \\
\text { "One Firm" } \\
\text { Altamente competitivo }\end{array}$ \\
\hline Expertise & $\begin{array}{l}\text { Visão estrutural } \\
\text { Equipes para a solução de proble- } \\
\text { mas empresariais } \\
\text { Entender o problema } \\
\text { Negociar com o cliente } \\
\text { Background em consultoria } \\
\text { Solução de problemas }\end{array}$ & $\begin{array}{l}\text { Visão Processual } \\
\text { Portfólio de ofertas (pacotes) } \\
\text { para ampla gama de problemas } \\
\text { empresariais } \\
\text { "the best way of doing } \\
\text { Ithinghs" } \\
\text { Background em auditoria } \\
\text { Venda de Soluções }\end{array}$ \\
\hline $\begin{array}{l}\text { Ritos } \\
\text { organizacionais }\end{array}$ & $\begin{array}{l}\text { Processo de avaliação e promoção } \\
\text { anual. } \\
\text { "Chegar a sócio" }\end{array}$ & $\begin{array}{l}\text { Processo de avaliação e } \\
\text { promoção anual } \\
\text { "Chegar a sócio" } \\
\text { Festa de final de ano - celebrar } \\
\text { a vitória }\end{array}$ \\
\hline
\end{tabular}

Quadro 1: Resumo das principais diferenças coletadas durante as entrevistas Fonte: Elaborado pelos autores 


\begin{tabular}{|c|c|c|}
\hline & Coopers\&Lybrand & Arthur Andersen \\
\hline Estórias e mitos & $\begin{array}{l}\text { Trabalho duro e sucesso } \\
\text { Estar à frente, ser líder }\end{array}$ & $\begin{array}{l}\text { Mito dos melhores } \\
\text { Trabalho duro e sucesso } \\
\text { Estar à frente, ser líder }\end{array}$ \\
\hline Tabus & Não identificado & $\begin{array}{l}\text { Discordar do sócio frontalmen- } \\
\text { te, quebra da hierarquia, "falta } \\
\text { grave" }\end{array}$ \\
\hline Sócios & $\begin{array}{l}\text { Admiração, mais próximos } \\
\text { Convencem ao invés de mandar } \\
\text { Líder da equipe } \\
\text { Presente no dia a dia } \\
\text { Consultoria/formação básica }\end{array}$ & $\begin{array}{l}\text { São vistos com certo } \\
\text { distanciamento e admiração } \\
\text { Não se incomodam de mostrar } \\
\text { seu poder e status } \\
\text { Falam alto para quem quiser } \\
\text { ouvir } \\
\text { Situação mais crítica: } \\
\text { transparecer falta de controle } \\
\text { Auditoria/formação básica } \\
\text { Distanciamento e Respeito }\end{array}$ \\
\hline $\begin{array}{l}\text { Relações no } \\
\text { trabalho }\end{array}$ & $\begin{array}{l}\text { Contatos se dão entre os membros } \\
\text { da equipe que envolve todos os } \\
\text { níveis } \\
\text { O contato com sócios é constante e } \\
\text { serve para orientação5 } \\
\\
\text { Baixo autoritarismo nas relações } \\
\text { chefe/subordinado } \\
\text { Diferença de salários entre a base e } \\
\text { o topo é grande, porém menor que } \\
\text { na Arthur Andersen } \\
\text { Superiores possuem privilégios } \\
\text { exclusivos (carro, garagem), } \\
\text { noentanto, menos discrepantes }\end{array}$ & $\begin{array}{l}\text { Contatos se dão predominante- } \\
\text { mente entre um nível e o } \\
\text { superior/inferior imediato } \\
\text { tornando-se mais raros quanto } \\
\text { maior a distância hierárquica. } \\
\text { A oportunidade de contato com } \\
\text { sócios é altamente valorizada e } \\
\text { tida como símbolo de status } \\
\text { Quanto menor a posição na } \\
\text { hierarquia, maior o conceito de } \\
\text { pessoa como "recurso a ser } \\
\text { alocado" - assistente } \\
\text { Viés autoritário nas relações } \\
\text { chefe-subordinado } \\
\text { Diferença de salários entre a } \\
\text { base e o topo é grande } \\
\text { Superiores possuem privilégios } \\
\text { exclusivos (ticket maior, carro, } \\
\text { garagem, restaurante exclusivo, } \\
\text { etc.) }\end{array}$ \\
\hline
\end{tabular}

Quadro 1: Resumo das principais diferenças coletadas durante as entrevistas Fonte: Elaborado pelos autores 
Analisando os elementos da lógica dominante (PRAHALAD; BETTIS, 1985) e da competência central (PRAHALAD; HAMEL, 1990), conclui-se que as duas organizações possuíam discrepâncias na forma como interpretavam o mundo, desenvolviam suas estratégias e decidiam a alocação de seus recursos. Isso gerou diferentes histórias e trajetórias individuais, fazendo com que a forma que os executivos viam e avaliavam a realidade fosse distinta $e$, portanto, geravam ações diferentes na realização das atividades e nos processos de tomada de decisão.

Em última instância, pode-se apontar as diferenças de competência central entre as duas firmas como o motivo causador de forte disputa na alocação de recursos, o que gerou e arraigou conflitos internos no processo de integração. Essa disputa fez com que a empresa resultante do processo de fusão tivesse dificuldade de definir metas e operacionalizá-las, não atendendo às demandas do ambiente externo. A empresa perdeu clientes, não acompanhou mudanças de mercado, reduziu a sua visibilidade e, por conseguinte, sua rentabilidade.

Nesse caso específico, o processo de fusão não trouxe efeitos positivos, sendo que muitos recursos foram perdidos pelo confronto entre as lógicas dominantes e competências centrais originais. Tais recursos acabaram se dispersando ao invés de contribuir para a geração de sinergias operacionais, gerenciais ou de mercado. Destaca-se que nenhum recurso foi perdido por falta de análise objetiva do processo, mas por aspectos subjetivos derivados da lógica dominante e da competência central.

\section{Conclusão}

Conforme argumentou-se no início deste artigo, a literatura especializada em fusões e aquisições não trata os conceitos de competência central e a lógica dominante como um possível entrave ou catalisador no processo de integração entre duas empresas. A Lógica Dominante vista na análise do caso apresentado pode ser uma forte fonte de conflito na alocação dos recursos.

Diferenças na Lógica Dominante e na competência central entre grupos oriundos de empresas distintas fazem com que gestores de determinada companhia vejam e avaliem a situação de forma diferente e, portanto, a prioridade para a alocação de recursos também será diferente. A disputa na alocação de recursos poderá gerar ou arraigar os conflitos internos no pro- 
cesso de integração. E a forma como se dá a alocação de recursos pela lógica dominante pode causar descontentamento de uma ou de ambas as partes. A disputa pode fazer com que a empresa tenha dificuldade de definir suas metas e como operacionalizá-las, gerar lentidão na tomada de decisão e finalmente levar à perda de capacidade de se ajustar às demandas do ambiente externo.

No caso analisado, que focaliza empresas de consultoria, isso é particularmente acentuado, pois a resposta ao ambiente tem que ser rápida devido à exigência constante de novos serviços. A lentidão pode significar perda importante de clientes e o não acompanhamento do mercado, reduzindo a visibilidade da empresa e, por conseguinte, sua rentabilidade e até sua capacidade de sobrevivência.

A diferença entre as lógicas dominantes se torna mais ou menos evidente de acordo com a complexidade organizacional e a estabilidade do ambiente externo. A não atenção às consequências do choque entre lógica dominante e da competência central das empresas envolvidas pode criar grupos antagônicos. Nesse sentido, cada grupo tem a sua visão sobre a forma certa de alocar os recursos para responder a demandas e problemas, frequentemente não sendo capazes de observar a necessidade de dialogar uma nova formação para a lógica dominante por meio de aprendizado mútuo.

Adicionalmente, foram identificadas algumas dimensões (variáveis) que permitiram contrastar as diferenças entre as lógicas dominantes de cada uma das empresas envolvidas no processo. Resumindo: mercados e tipos de serviços com os quais a alta gerência e os sócios desenvolveram sua formação $e$ expertise, estrutura de carreira na empresa, experiência média no negócio, perfil do consultor e modelo de remuneração.

A forma como as pessoas interpretam o ambiente, conceituam o negócio e fazem a alocação dos recursos é fundamental dentro de um processo de fusão e aquisição. Dado que as histórias de cada empresa e de seus indivíduos são distintas, a maneira pela qual eles interpretam o mundo e conceituam o negócio também terá diferenças.

As diferenças são, nesse sentido, naturais e estarão presentes desde o início, cabendo um processo de negociação interna para que a Lógica Dominante e a competência central das empresas consigam gerar uma outra lógica, que seja capaz de capacitar a empresa resultante em alocar os recursos originários evitando perdas. É importante que os dirigentes envolvidos no processo de fusão reconheçam e percebam as limitações que podem ser cau- 
sadas pelas diferenças de lógica dominante e pelos fatores cognitivos no processo de integração.

Um problema central é que, na maior parte das vezes, tanto lógica dominante quanto competência central são de difícil acesso para a análise racional realizada a priori. Justamente por seu caráter subjetivo e seu enraizamento profundo nos modos de pensar dos líderes organizacionais. Nessa direção, o descolamento entre "o que é" objetivamente pensado e o "como é interpretado" subjetivamente é praticamente impossível.

Este artigo buscou trazer os aspectos da racionalidade limitada, da Lógica Dominante para a análise de processos de fusão e aquisição. Entendese ser este o primeiro passo para mais pesquisas nessa linha teórica, que, se aprofundadas, podem orientar na avaliação e planejamento de um processo de fusão.

Esses resultados podem abrir interessantes campos de pesquisa futura. Para professores e pesquisadores, o presente trabalho ressalta a necessidade de se examinar as tradicionais teorias sobre fusões e aquisições antes de pressupor sua validade universal. Nessa linha, o artigo sugere fortemente a necessidade de prosseguir com a discussão da competência central e Lógica Dominante como elemento importante na análise de processos de fusão $e$ aquisição. Imagina-se que uma vasta possibilidade de pesquisa pode ser aberta para estender a pesquisa para outros casos e contextos, visando verificar se as conclusões aqui apresentadas se confirmam. A tarefa de discutir e validar conceitos é de grande importância para que decisões sobre fusões e aquisições, que são uma das principais decisões estratégicas, não sejam tomadas sobre premissas falsas, ultrapassadas ou não adequadas. Com este artigo espera-se colaborar nesse sentido, mas o aprofundamento por meio de outros estudos e pesquisadores se faz essencial para que tal proposta tenha eco e sucesso nesse campo. 


\section{Core Competence and Dominant Logic: contributions to the analysis of merger and acquisition process}

\section{Abstract}

Mergers and acquisitions are one of the most important strategic decisions a company can take. In the 1980s and 1990s, mergers and acquisitions have occurred in large numbers of companies and several theories have been developed to explain the phenomenon. However, most of these theories are related to the financial area. But, non-quantifiable aspects, such as core competencies and dominant logic, have been relegated to the background. Identified this gap, this paper proposes the inclusion of the concept of core competence and dominant logic as an analytical tool to validate a merger process. To do so, this article has rescued the discussion of these concepts in the business strategy field and a case that did not achieve the proposed goals with the merger was examined from this perspective. The result evidence that the adoption of the concepts of core competence and dominant logic helps explain a new insights with the merger process.

Key words: Strategy. Mergers and Acquisitions. Core Central. Dominant Logic.

\section{Referências}

BETTIS, Richard A.; PRAHALAD, C. K. The dominant logic: retrospective and extension. Strategic Management Journal, 16, 5-14, 1995.

DATTA, D. K. Organizational fit and aquisition performance: effects of postaquisition integration. Strategic Management Journal, 281-97, 1991.

DOZ, Yves, L.; PRAHALAD, C. K. Headquarters Influence and Strategic Control in MNCs, Sloan Management Review, Cambridge; Fall, v. 23, Iss. 1, p. 15, 1981.

EISENHARDT, Kathleen M. Building theories from case study research. The Academy of Management Review, v. 14, n.4, p. 532 - 550, Oct., 1989. 
FOWLER, K. L.; SCHMIDT, D. R. Tenders to offres, aquisition and subsequent performance in manufacturing firms. Academy of Management Journal, 31, 4, 962-74, 1988.

HUNT, J. W. Changing pattern of acquisition behavior in takeovers and the consequences for acquisition process. Strategic Management Journal, 11, 1, 69-78, 1990.

LUBATKIN, M. Merge strategies and stock holder value. Strategic Management Journal, 8, 39-53, 1987.

MARCH, James G.; SIMON, Hebert Organizations. New York: Wiley, 1958.

MONTGOMERY, C. A.; WILSON, V. A. Research note and Communication: merges that last: a predictable pattern? Strategic Management Journal, 7, 91-6, 1986.

PRAHALAD, C. K. Strategic choices in diversified MNCs, Harvard Business Review, jul-aug, v. 54, Iss. 4; p. 67, 1976.

PRAHALAD, C. K.; BETTIS, R. A. The dominant logic: A new linkage between diversity and performance. Strategic Management Journal, 7, 485-501, 1986.

PRAHALAD, C. K.; HAMEL, G. The core competence of the corporation. Harvard Business Review, Boston, p. 79-91, may, 1990.

SMIRCICH, Linda. Studying Organization as culture. In: MORGAN, G. (Ed). Beyond Method: strategies for social research. Beverly Hills: Sage, 1983.

WEICK, Karl E. Improvisation as a mindset for organizational analysis.

Organization Science, Linthicum, v. 9, Iss. 5; p. 543, 13,1998.

YIN, Robert K. Estudo de caso: planejamento e métodos. 2. ed. Porto Alegre: Bookman, 2001. 